\section{Problems at Max Planck}

SIR-I would like to respond to your article on the structural problems of the Max Planck Society (MPS) (Nature 340; 335; 1989).

The MPS does not consist only of directors and slaves; there is also a sizeable number of middle-rank employees (equivalent to tenured associate professors in US universities) whose scientific reputation is independent of the director. They run their own groups and programmes, with much of their support coming from outside grants. Many of them have come back to West Germany from good overseas posts, hoping to use their positions either to move up within the MPS or to obtain a university professorship. To the frustration of many of them, (1) the low level of institutional recognition given to them makes a career within MPS highly unlikely, and (2) the congestion at the top of West German universities, both in terms of available professorships and resources, seriously limits their flexibility. At present, these group leaders face the same dark future as other employees left behind when a director retires.

Many of the current problems of the MPS could be solved if the society would develop an attractive career system for younger scientists similar to that of tenure-track positions in US universities. The independence of scientists should parallel their ability to carry out independent research, their motivation should be fostered by a reasonable outlook and institutional recognition, and the MPS should develop a system of internal competition for resources. A fresh approach is necessary in which the present privileges and endowments of MPS directors are more reasonably divided between all the members of the MPS community. The hope is with the new generation of directors but a chorus of voices is required in order to be heard.

ALFRED MAELICKE

\section{Max-Planck-Institut \\ für Ernährungsphysiologie, \\ Rheinlanddamm 201,}

D-4600 Dortmund 1, FRG

SIR-The article on the Max-Planck Society (MPS) highlights one of the structural problems this society has. In addition, there is at least one other problem. The MPS has chosen to employ particularly able scientists on tenured contracts equiv alent to those of middle-rank professor at the universities. Their number is about 200 and thus similar to that of the directors. Many of them function as group leaders on projects that are independent although often related to that of the director, and always dependent on him for resources. This group of scientists contribute greatly to the reputation of the MPS. Yet, as the
MPS has failed to make provision for such groups as independent units, the society sees their existence as a private arrangement with the director, with the consequence that resources will be cut off when the director retires. These colleagues have been chosen on their scientific merit and in many cases are expected to run a group, so it is a slap in the face that their scientific career in the MPS should essentially be terminated with that of the director. The MPS recognizes as units only departments with directors as heads. Rare exceptions are the groups for junior scientists established on a five-year basis. Although there might have been a justification for this hierarchical structure in earlier days, it is inadequate for a research organization nowadays. It should be adjusted to present-day requirements by giving autonomy to the de facto existing mid-level positions. The MPS would benefit from such a change by a decrease in size of departments and the creation of a livelier, more stimulating atmosphere in the institutes.

\section{Max-Planck-Institut für}

F. ECKSTEIN

Experimentelle Medizin, Hermann-Rein-Strasse 3, D-3400 Göttingen, FRG

\section{Reason to write}

SIR-As a scientist and a member of the human rights group Amnesty International, I would like to bring to the attention of the scientific community one of the many human stories that underlie the brutal repression in China in the past several months. Nature has reported on the events in China, and on some of the arrests that have occurred in the Chinese scientific community (for example $\mathbf{3 4 0}$, $174 ; 1989)$. Among those arrested in the crackdown was Yang Wei.

Yang Wei was one of the many Chinese students to go abroad in the past ten years, spending several years as a molecular biology student at the University of Arizona. Many of us have had the privilege of meeting such students. As they learned about science, we watched as they adapted to the West and learned about the freedoms we enjoy.

Yang Wei was unfortunate enough to have been at home for a visit during the earlier round of student demonstrations, and he was among those arrested in January 1987 and imprisoned. During his imprisonment he was adopted as a prisoner of conscience by Amnesty International. His two-year prison term ended in January this year, and he was awaiting permission to return to his studies in the United States, and to rejoin his wife, also a student here. These plans came to nothing on 19 July, when he was arrested again allegedly for involvement in the recent round of demonstrations.

Any of the thousands of Chinese students abroad could be Yang Wei, imprisoned for speaking out, something we had taught them to do, both directly and by example. Seeking out the truth and speaking it underlie the ideal of scientific enterprise. We cannot abandon our colleagues in China who are now being punished for speaking the truth. One way to remember them is to write to Prime Minister Li Peng (Guowuyan, Beijingshi/ People's Republic of China) on behalf of Yang Wei, expressing concern at the reports of arbitrary arrests such as his. We must remind the Chinese leaders that we will not forget the events of June or their aftermath.

Department of Biology,

MARK PEIFER

Princeton University,

Princeton,

New Jersey 09544, USA

\section{Pitt not Penn}

SIR-A leading article on "Conflicts of interest" (Nature 340, 664; 1989) commented on "the dispute that has now come to light at the University of Pennsylvania". However, it is stated on page 668 that the dispute on conflicts of interest is at the University of Pittsburgh. Please note that the University of Pennsylvania, named for William Penn, is the one founded by Benjamin Franklin in 1740 and is beginning its 250th anniversary celebrations. The University of Pittsburgh, which has the dispute, was named for William Pitt the Elder, and was chartered in 1787. Although it is a university in Pennsylvania, it is not the University of Pennsylvania and is more than 300 miles away from here.

University of Pennsylvania,

Philadelphia,

Pennsylvania 19104, USA

\section{Women in physics}

SiR-Only 130 out of 1,302 doctorates granted in physics in the United States in 1988 went to women (Nature 340, 417; 1989).

In the same issue, you wrote "By now, of course, every schoolboy knows that the quintessential point in space-time is the occasion of the Big Bang ..." (Nature 340, 425; 1989)

Thank you for pointing out that the underrepresentation of females in physics begins at an early age.

KELLIE NEET

DAVED FREMONT

University of California, San Diego,

La Jolla

California 92037 USA 